Monatsschrift für Geburtshülfe u. Gynäkologie 1913;37:670

\title{
Frantz Howitz $\dagger$
}

\section{$1828-1912$.}

Am 23. XII. verschied zu Kopenhagen Prof. Frantz Howitz in seinem 84. Lebensjahre. Sein Leben war nicht nur reich an Jahren, sondern auch an Taten. Als junger Assistenzarzt schloß sich H. der Semmelweißsch $\beta$ n Lehre an, konnte aber mit seinen Anschauungen nicht durchdringen. Von da an widmete sich H. fast ausschließlich der Gynäkologie; obgleich er die Universitätsprofessur nicht erreichte, stand er hoch da viele Jahre hindurch als der Lehrer in diesem Fache, nicht nur für Dänemark, sondern für ganz Skandinavien. Als erster in Dänemark führte er (im Jahre 1863) die Ovariotomie aus und folgte auf Schritt und Tritt den Fortschritten der operativen Gynäkologie in Deutschland, England und Frankreich. Neben seiner praktischen Tätigkeit entfaltete $\mathrm{H}$. auch eine große literarische Wirk-samkeit und verstand es wie wenige, auch seine jungen Schüler zur Arbeit anzuregen. Neben seinen Leistungen auf dem Gebiete der Gynäkologie verdient rühmend erwähnt zu werden, daß H. es als erster empfahl, gegen Myxödem die Gland, thyreoidea zu essen.

In den letzten Jahren, wo H. seine praktische Tätigkeit aufgegeben hatte, nahm er mit lebhaftem Interesse teil an den modernen Bestrebungen, so am Kampfe gegen den Krebs.

Ein ausgezeichneter Arzt, ein hervorragender Lehrer, ein hoch-begabter Mann ist mit Howitz dahingeschieden.

Ehre seinem Andenken!

Leop. ikfeÿer-Kopenhagen. 